\title{
A dedicated battery for an electric bike
}

\author{
Jarosław Jajczyk ${ }^{1, *}$, Kamil Słomczyński ${ }^{1}$ \\ ${ }^{1}$ Poznan University of Technology, Faculty of Electrical Engineering, Piotrowo 3A, 60-965 Poznan, Poland
}

\begin{abstract}
The project presents a dedicated battery for an electric bicycle. Information on the structure of the vehicle and the principles of operation were given. An electric drive consisting of a brushless motor was characterized. The process of designing and making the battery is presented. The battery has been developed in a universal way, allowing installation in other constructions. The test results of the developed battery have been presented.
\end{abstract}

\section{Introduction}

Ecological and increasingly economic aspects contribute to the increase of interest in alternative (unconventional) methods of powering vehicles. Recently, electric vehicles have gained in popularity [1-5]. One of the interesting solutions is the use of electric drive in bicycles. The main advantages of using an electric bike include:

- emission-free work,

- speed of travel,

- ease of parking,

- relatively low purchase cost,

- lower travel costs than in the case of combustion vehicles.

An additional argument in favor of the electric bicycle is the reduction of noise emissions. It is possible to convert a classic bicycle to an electric bicycle, thus reducing construction costs. A bike with a suitable construction is required, i.e. allowing the assembly of the engine, battery, controller and additional equipment. The possibility of storing a bicycle in rooms minimizes the risk of adverse weather conditions (especially on batteries) or unauthorized persons.

Electric bicycles are divided due to the location of the engine driving the bike (wheel hub or centrally in the bicycle frame) [1]. The main benefits of locating the engine in the rear wheel are: the weight distribution of the vehicle, the simplicity of repair and the possibility of converting a classic bike into an electric bicycle. This is a very popular solution due to the lack of mechanical alterations in the bike. In the second solution the biggest advantage is the low center of gravity. The engine is mounted in the lower part of the frame. An additional advantage of this solution is the visual unity of the frame motor. In this case, disassembly or repair are more difficult and require specialized equipment. This solution is more expensive due to the need to fully match the engine to the geometry of the vehicle.

\section{Project of electric drive}

The design of an electric bike's drive consists of three basic elements: an electric motor [6], a battery and a controller (Figure 1).

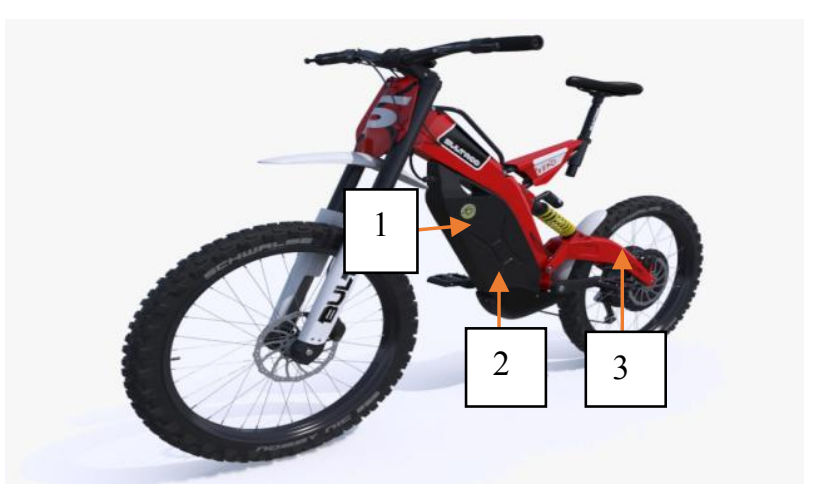

Fig. 1. An electric bicycle consisting of: 1 - battery, 2 - controller, 3 - engine [2]

The work assumes that the bike will be powered by a $3000 \mathrm{~W}$ motor at $48 \mathrm{~V}$ power supply. It is a relatively high power that allows you to get satisfactory results while driving. The brushless motor is chosen for quiet operation.

\section{Dedicated battery}

Lithium-ion cells were used to produce the battery. The decisive features are the lack of memory effect, easy availability of cells and the best capacity to mass ratio $[3,4,5,7,8,9]$. The battery must have a rectangular shape to fit into the dedicated frame of the bicycle. The controller and the motor require a $48 \mathrm{~V}$ voltage supply because a $13 s 8 p$ battery has been designed ( 8 chains of 13 cells each). For its construction, 104 cells of the Samsung 35E [10] were used (Figure 2). 


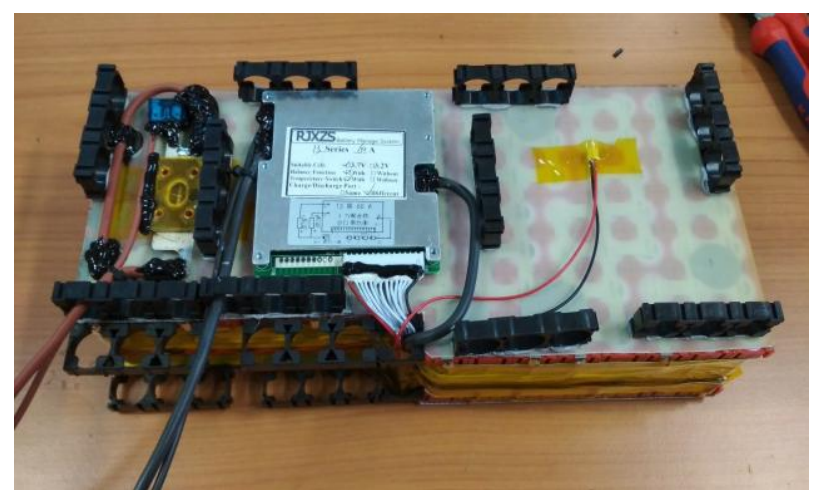

Fig. 2. Battery after welding of cells and BMS system

The built-in battery has a rated voltage of $48.1 \mathrm{~V}$, a capacity of $28 \mathrm{Ah}$ and a maximum discharging current of $80 \mathrm{~A}$. The cells are divided into sections so that the cells from one section have as many connections as possible and touch as much as possible. The cells were welded to the appropriate packages.

In order to increase the reliability of the battery, it was decided to use a battery management system (BMS). It's an additional element that is responsible for supervising the charging and discharging of the battery, equalizing the voltage in the cells, not completely discharging the battery and automatically disconnecting the charger after the failure $[11,12]$.

\section{Battery test}

Battery has been tested in laboratory conditions. The test consisted of charging the battery to $100 \%$ and then connecting it to the unloading device. The voltage waveform is marked in blue, whereas the current is discharged in red (Figure 3). The initial voltage at which the test was started was $54.61 \mathrm{~V}$. The test battery was charged with a current of $20 \mathrm{~A}$. From the graph it can be read that the cut-off voltage (BMS activation) is about $36 \mathrm{~V}$. The measured capacity was at $26.89 \mathrm{Ah}$.

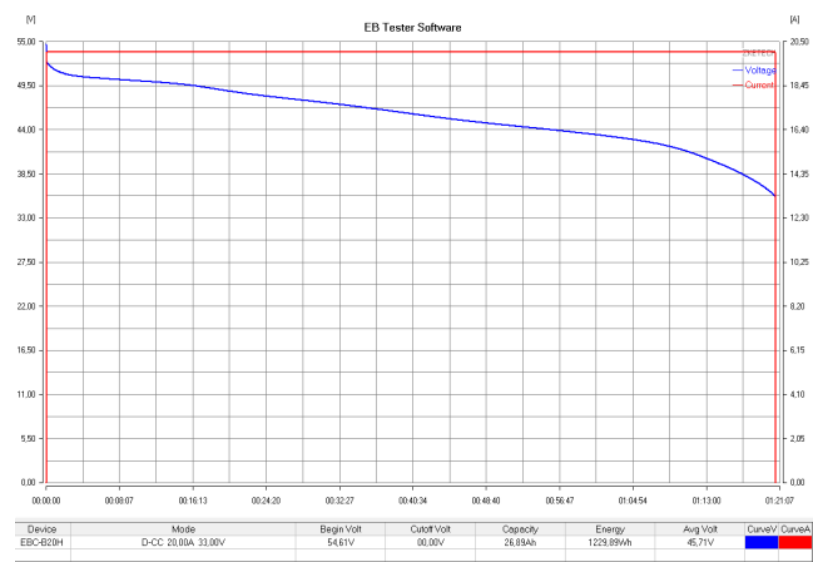

Fig. 3. Battery discharge characteristics

Next, the tests consisted in measuring the battery voltage in road conditions. The test was carried out while driving at a constant speed of $20 \mathrm{~km} / \mathrm{h}$. The voltage on the battery was read at 30-minute intervals (Figure 4).

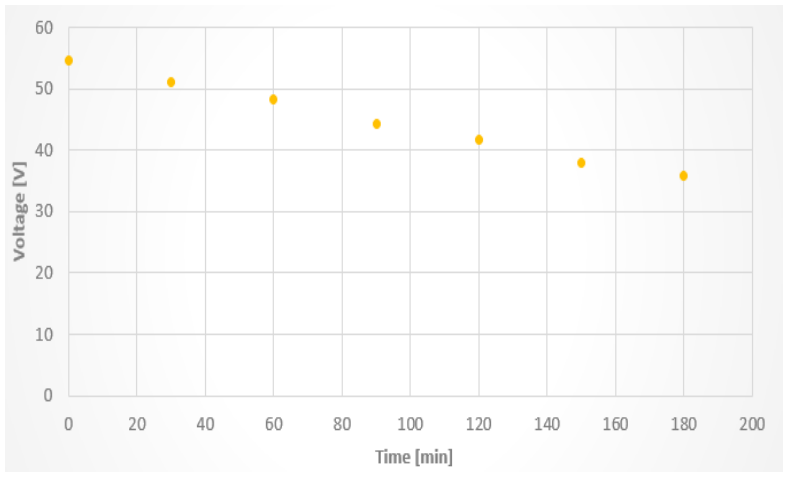

Fig. 4. Characteristics of discharging the battery in road conditions

The test was carried out at $29^{\circ} \mathrm{C}$. After $\sim 3 \mathrm{~h}$, the battery controller has disconnected the battery, making it impossible to continue driving with electric assistance. The range in this test was about $60 \mathrm{~km}$. The maximum reach of a bicycle that was achieved by moving with a lower and topography-dependent speed was about $85 \mathrm{~km}$.

\section{Conclusions}

The paper presents a lithium-ion battery with a nominal voltage of $48.1 \mathrm{~V}$ and a capacity of $28 \mathrm{Ah}$, which was designed for an electric bicycle equipped with a $3 \mathrm{~kW}$ motor. The battery was tested in laboratory conditions that confirmed the assumed capacity and in road conditions on the basis of which the actual range of the bicycle was determined. Both studies confirmed the usefulness of the developed solution.

\section{References}

1. M. Kędracki, Bike Board Rowery Elektryczne, (N.R.G., Kraków, 2, 2018)

2. https://www.turbosquid.com/3d-models/3d-electricbike-bultaco-brinco-model-1150027 (2019)

3. A. Czerwiński, Akumulatory baterie ogniwa, (WKŁ, Warszawa, 2012)

4. A. Dobrzycki, M. Filipiak, J. Jajczyk, D. Kurz, E3S Web Conf., 19, 01027 (2017), doi: 10.1051/e3sconf/20171901027

5. A. Dobrzycki, M. Filipiak, J. Jajczyk, ITM Web Conf., 19, 01034 (2018)

6. Ł. Knypiński, L. Nowak, COMPEL, 30, 929-940 (2011)

7. J. Jajczyk, W. Lorkiewicz, ITM Web Conf., 19, 01036 (2018)

8. L. Kasprzyk, Prz. Elektrotechniczny, 95/3, 70-73 (2019)

9. D. Burzyński, D. Głuchy, M. Godek, ITM Web of Conferences 19, 01025 (2018)

10. Specification of Lithium-ion rechargeable cell Model name: INR18650-35E, Samsung SDI Co., Ltd. Cell Business Division, (2015)

11. A. Dobrzycki, S. Mikulski, W. Opydo, Appl. Sci., 9, 1523 (2019)

12. K. Bednarek, R. Nawrowski, A. Tomczewski, Prz. Elektrotechniczny, 84/01, 62-64 (2008) 